\section{Binge drinking and associated factors among adolescents in a city in southeastern Brazil: a longitudinal study}

\author{
Consumo excessivo de álcool e fatores \\ associados entre adolescentes de cidade do \\ Sudeste brasileiro: um estudo longitudinal \\ Consumo excesivo de alcohol y factores \\ asociados entre adolescentes de ciudad del \\ sudeste brasileño: un estudio longitudinal
}

\begin{abstract}
The aim of this study was to investigate changes in the frequency of binge drinking and associated factors in the city of Belo Horizonte, Minas Gerais State, Brazil. The sample consisted of 436 adolescents. Data collection involved the Alcohol Use Disorders Identification Test and the Alcohol, Smoking and Substance Involvement Screening Test. Ordinal logistic regression was used in the multivariate analysis. An increase in the frequency of binge drinking was found among adolescents who lived in areas of greater social vulnerability $(O R=1.64 ; 95 \% C I: 1.01-2.68)$, those whose mothers consumed alcoholic beverages $(O R=1.75$; 95\%CI: 1.05-2.92), those whose fathers consumed alcoholic beverages $(O R=2.02 ; 95 \% C I: 1.11-3.68)$, those with an increased risk of tobacco use $(O R=2.82 ; 95 \% C I$ : $1.07-7.42)$ and those who attended religious services (OR $=2.10 ; 95 \% \mathrm{CI}: 1.30-3.38)$. Knowledge regarding factors associated with a change in the frequency of binge drinking among adolescents can assist in the establishment of public policies directed at health promotion and the prevention of adverse health conditions.
\end{abstract}

Binge Drinking; Alcoholic Beverages; Adolescent
Kelly Oliva Jorge 1

Raquel Conceição Ferreira 1

Efigênia Ferreira e Ferreira 1

Miriam Pimenta Vale 1

Ichiro Kawachi 2

Patrícia Maria Zarzar 1

doi: 10.1590/0102-311X00183115

\section{Correspondence}

K. O. Jorge

Av. Presidente Antônio Carlos 6627, Belo Horizonte, MG 31270-901, Brasil.

kellyoliva@yahoo.com.br

1 Universidade Federal de Minas Gerais, Belo Horizonte, Brasil. 2 Harvard University, Boston, U.S.A. 


\section{Introduction}

The excessive consumption of alcoholic beverages is a major public health problem in many countries 1 . Binge drinking (the consumption of five or more alcoholic drinks on a single occasion) ${ }^{2}$ seems to be associated with a number of biological, cultural, economic, environmental, psychological and social consequences 3,4 and can predispose adolescents to traffic accidents, violence and areater risk of alcoholism 5,6 .

The prevalence of alcohol use among adolescents varies in different parts of the world. In a study carried out in northwest England, the majority of adolescents between 15 and 16 years of age (84\%) reported drinking alcohol at least occasionally and over one third of the drinking participants (36.3\%) reported binge drinking 2. In Brazil, Sanchez et al. 7 found a binge drinking rate of 32\% among students in all five Brazilian macro regions. A similar prevalence rate was found among students aged 15 to 19 years in the city of Belo Horizonte (36\%) 8 .

Among socio-demographic factors associated with alcohol consumption, age 9 , the male gender, Caucasian ethnicity, a lower level of education 10,11,12 and engaging in substance use 10,13 are generally related to a greater prevalence rate of alcohol use. The increase in age is related to a greater occurrence of the use of psychoactive substances. According to Kalaydjian et al. 11, the onset of each stage of alcohol use, whether first use, regular use, abuse or dependence, undergoes the sharpest increase in the decade between the early teens and the early 20s. Half of all projected lifetime users begin use by age 16 to 17 and more than half of all projected lifetime abusers and individuals with lifetime dependence meet the criteria for these disorders by the age of 21 . The vast majority (over 90\%) of projected lifetime abuse-dependence begins by the mid-30s.

A family problem, such as substance use, is also an important predictor of alcohol problems 1 . In a study conducted in Canada, Mistry et al. 14 found that adolescents who live with parents who consume alcohol tend to exhibit the same behavior. In an epidemiological study conducted in the city of São Paulo, Brazil, the authors concluded that living with family members that do not consume alcoholic beverages reduces the chance of binge drinking by $44 \% 4$.

Some studies have demonstrated that adolescents with a low socioeconomic status have a greater propensity toward the use of alcoholic beverages and binge drinking 14,15,16. A meta-analysis of marijuana and alcohol use by socioeconomic status in adolescents concluded that adolescents with lower socioeconomic status have greater risk behavior than adolescents with higher socioeconomic status 17 . On the other hand, Brazilian epidemiological studies have found an association between a higher socioeconomic status and binge drinking 7,8,18,19. According to a review about the relationship between socioeconomic status and health-related behaviors in adolescence, the existence of an association between socioeconomic status and alcohol use is not evident in the studies analyzed, but would require further analysis in different countries to improve the evidence 20.

The influence of religious factors on substance use has piqued the interest of researchers. Studies report a lower chance of exposure to alcohol and lifetime use among adolescents involved in religious practices 21,22,23. The National Longitudinal Study of Adolescent Health in the USA found that both public and private domains of religiosity were protective against cigarettes, alcohol and marijuana use. The public religiosity variable combines two items measuring frequency of attendance at religious services and frequency of participation in religious youth group activities. The private religiosity variable combines two items measuring the frequency of prayer and importance of religion. Upon closer examination, it appeared that private religiosity was more protective against experimental substance use, while public religiosity was more associated with regular use of alcohol 24.

Despite concerns regarding excessive alcohol use among adolescents, little information has been published on factors associated with the progress of excessive drinking throughout the course of one's life 1,11. The lack of information on socio-demographic predictors of the transition of alcohol intake constitutes an obstacle to the identification of high risk individuals and the planning of prevention programs 11. Alcohol consumption, especially when initiated at a young age, places health and wellbeing at risk 9 . Special attention should be given to habits developed in adolescence as predictors of alcohol abuse in adulthood 1. The analysis of changes in the frequency of binge drinking among adolescents and associated factors is essential to the establishment of early interventions aimed at preventing negative impacts in adulthood. 
Considering the possible influence of substance use, family factors, socioeconomic status and religiosity on excessive alcohol consumption among adolescents, the aim of the present longitudinal study was to investigate the association of these factors in relation to changes in the frequency of binge drinking among adolescents at public and private high schools in the city of Belo Horizonte, Brazil.

The following hypotheses were tested: (i) Substance use by adolescents increases the frequency of binge drinking; (ii) Alcohol consumption by parents is associated with the frequency of binge drinking by adolescents; (iii) A better socioeconomic status is associated with an increase in the frequency of binge drinking among adolescents; (iv) Participating in religious services is a protective factor against the increase in the frequency of binge drinking by adolescents.

\section{Methods}

\section{Subjects, setting and period of recruitment}

A longitudinal study was conducted in the city of Belo Horizonte, involving two evaluations of alcohol intake with two-year intervals between evaluations. Belo Horizonte is the capital of the state of Minas Gerais in southeastern Brazil; it has approximately 2.4 million inhabitants and is geographically divided into nine administrative districts (Instituto Brasileiro de Geografia e Estatística. http://www.ibge.gov.br/home/estatistica/populacao/contagem, accessed on 10/Jul/2013). A total of 117,547 and 25,569 15-to-19-year-old students are enrolled in 820 public and 434 private schools, respectively (Instituto Nacional de Estudos e Pesquisas Educacionais Anísio Teixeira. http://portal. inep.gov.br/basica-censo-escolar-matricula). A full list of all students enrolled in public and private schools was obtained from the Belo Horizonte Education Secretariat and the distribution of students in each of the nine administrative districts was calculated. At the baseline assessment in 2010, a study was conducted with a representative sample of 936 high school students aged 15 to 19 years attending public schools $(\mathrm{n}=717 ; 81 \%)$ and private schools $(\mathrm{n}=174 ; 19 \%)$ in the city of Belo Horizonte. Further details on the sample are found in a previously published study 25 .

As the intention was to evaluate high school students over a two-year period, the sample was limited to students who were 15 and 16 years of age in the baseline survey (2010) and who were expected to still be in high school two years later $(\mathrm{n}=529)$. In 2012, a new data collection procedure was carried out with these adolescents when they were aged 17 to 19 years. However, 26 of them were not identified due to incomplete demographic data, 19 had dropped out of their respective schools and 48 had moved to a different address. Thus, the follow-up study involved a sample of 436 adolescents (with a loss of $17.5 \%$ ).

\section{Measures}

The adolescents were interviewed on two separate occasions. The Alcohol Use Disorders Identification Test (AUDIT C) validated for use in Brazil 26 was employed for the evaluation of alcohol intake. AUDIT helps identify whether an individual exhibits hazardous (or risky) drinking, harmful drinking or alcohol dependence 27 . AUDIT C (the first 3 questions on the AUDIT instrument, which are related to the frequency and amount of alcohol consumed) was used, as this version can be employed as a stand-alone screening measure to detect hazardous drinkers among adolescents 28,29: (a) "How often did you have a drink containing alcohol in the past year?"; (b) "How many drinks containing alcohol did you have on a typical day when you were drinking?"; and (c) "How often do you have five or more drinks on one occasion?". The latter item was used to identify binge drinking 4 . The response options are: never, less than monthly, monthly, weekly and daily or almost daily. Responses of "never" were coded as 0 in the analysis. "Less than monthly" and "monthly" were coded as 1 . "Weekly" and "daily or almost daily" were coded as 2 .

The dependent variable was a change in the frequency of binge drinking and was determined based on the difference in consumption between 2010 and 2012 and categorized as "reduced frequency intake", "unaltered frequency intake" and "increased frequency intake". The independent variables were 
demographic and socioeconomic characteristics [gender, type of school, Social Vulnerability Index (SVI), mother's schooling and frequency of attending religious services], family behavior regarding alcohol intake (relatives who drink, father who drinks and mother who drinks) and the concomitant use of other drugs (risk of tobacco and marijuana use). The following independent variables were collected on both occasions: gender, type of school (public or private), SVI, mother's schooling and members of the family who drink (yes/no). For statistical purposes, however, data on SVI, mother's schooling and members of the family who drink collected during the first interview were considered, as no significant differences were found between 2010 and 2012.

The SVI was used for the socioeconomic classification. The SVI has 20 variables grouped into five dimensions of citizenship: environmental (access to housing and basic infrastructure); cultural (access to education); economic (access to income and employment); legal (access to legal assistance); and security (access to health, food security and welfare) 30. The score ranges from 0 to 1 , with higher values denoting worse community conditions or greater vulnerability to social exclusion in the community in question. The Belo Horizonte database of SVI scores for each district was used, based on the address of each family. The students' addresses were collected individually. Each street is located in a region categorized into one of five classes. The SVI was dichotomized as less vulnerable (social classes III, IV and V; coefficients $\leq 0.49$ ) and more vulnerable (social classes I and II; coefficients > 0.49).

The Alcohol, Smoking and Substance Involvement Screening Test (ASSIST), validated for use in Brazil 31, was used for the evaluation of tobacco and marijuana use. This questionnaire is composed of eight questions on the use of nine classes of psychoactive substances (tobacco, alcohol, marijuana, cocaine, stimulants, sedatives, inhalants, hallucinogens and opiates). The items address frequency of use and related problems. A risk score ranging from 0 to 4 is provided for each substance and the total ranges from 0 to 20. The scores are grouped as follows: 0 to 3 indicates occasional use; 4 to 15 indicates abuse; and $\geq 16$ indicates dependence. The difference in scores between 2010 and 2012 was calculated to determine the change in risk of tobacco and marijuana use: unaltered risk, increased risk and reduced risk. For statistical purposes, the unaltered and reduced risk categories were pooled.

Religious participation among the adolescents and alcohol intake patterns among family members were evaluated during the second evaluation (2012) through the following questions: (a) "Do you have a religion? Which?"; (b) "How often do you frequent your place of worship?"; and (c) "Does anyone in your family drink alcoholic beverages? Who? (father/mother/siblings/others)" 21,22.

\section{Administration of questionnaires}

The participants filled out a socio-demographic form that was numbered and collected by the researcher. Questionnaires with the same numbering as the form were then distributed in the classroom by a researcher and assistant and collected immediately after being filled out. The questionnaires were used at baseline (2010) and follow-up (2012). The students were informed that the questionnaires would be under the responsibility of the researcher with no access allowed to parents or school officials. To guard against biases that may occur due to variability in reading proficiencies, the principal investigator (K.O.J.) read each question aloud. Students could refuse to participate and return incomplete questionnaires in the envelopes.

\section{Ethical considerations}

This study received approval from the Human Research Ethics Committee of the Federal University of Minas Gerais (protocol number 124/08) in accordance with the recommendations of the Declaration of Helsinki. Authorization was obtained from the selected schools to undertake the study. The participants and their parents/guardians signed a statement of informed consent.

\section{Statistical analysis}

Data analysis was performed using the Stata 12.0 statistical package (StataCorp LP, College Station, USA). The prevalence of binge drinking was calculated for both evaluations (2010 and 2012) and the comparison between proportions was performed using the McNemar test. Associations between the 
change in the frequency of binge drinking (the ordinal qualitative variable) and the independent variables were tested using the chi-square test (linear trend) $(\mathrm{p}<0.05)$. Variables significantly associated with a change in binge drinking ( $<0.25$ in the bivariate analysis) and those considered important in the literature regardless of the p-value were incorporated into the ordinal logistic regression analysis. The score test was performed to check the proportional odds assumption (chi-square $=22.58 ; \mathrm{p}=$ 0.002). The partial odds proportional model was chosen using the gologit 2 Statas' command 32 with the autofit option. The gologit 2 command tests the assumption of proportional odds using the autofit option and adjusts coefficients for the different categories of the independent variables for which this assumption is violated. For the multiple regression analysis, frequency of religious services was dichotomized with the combination of the "monthly" and "never" categories. The post hoc test was used to evaluate the test power of the sample considering the formula for the comparison of proportions with the prevalence and odds ratios obtained in the present study.

\section{Results}

Among the 436 participants, 260 (59.6\%) were female and 176 (40.4\%) were male, with a mean age of $17.6 \pm 0.52$ years. A total of $75.9 \%(n=331)$ studied at public schools and $24.1 \%(\mathrm{n}=105)$ studied at private schools. The majority of participants $(\mathrm{n}=227 ; 52.1 \%)$ lived in areas of lesser social vulnerability (social classes III, IV and V) and 338 (77.5\%) reported that a member of the family consumed alcoholic beverages. Regarding religiosity, 398 students (91.3\%) reported having a religion and 285 (65.4\%) reported attending services only once a month or not at all.

The prevalence of binge drinking was $35.6 \%$ in 2010 and $39.9 \%$ in 2012, which corresponds to a $4.3 \%$ increase in the period analyzed (McNemar test $=14.20 ; \mathrm{p}=0.003)$. Among the 281 adolescents who reported consuming five or more alcoholic drinks on a single occasion in 2010, 75 had engaged in binge drinking with greater frequency in 2012. Among those who engaged in binge drinking up to once a month in 2010 ( $\mathrm{n}=138), 21$ had begun to engage in binge drinking once a week or almost daily in 2012. Thus, 96 (22\%) of the 436 adolescents demonstrated an increase in the frequency of binge drinking. Among the binge drinkers in 2010, 61 (13.9\%) demonstrated a reduction in this practice by either not engaging in binge drinking $(\mathrm{n}=56)$ or reducing the frequency of binge drinking $(\mathrm{n}=5)$ (Table 1).

Changes in binge drinking patterns were associated with the frequency of participation in religious activities $(\mathrm{p}=0.004)$, having a family member who consumed alcoholic beverages $(\mathrm{p}<0.001)$,

\section{Table 1}

Distribution of sample in relation to changes in alcohol consumption (frequency of binge drinking) in 2010 and 2012. Belo Horizonte, Minas Gerais State, Brazil, 2012.

\begin{tabular}{|c|c|c|c|c|}
\hline \multirow{2}{*}{$\begin{array}{l}\text { Frequency of binge } \\
\text { drinking (2010) }\end{array}$} & \multicolumn{3}{|c|}{ Frequency of binge drinking (2012) } & \multirow[b]{2}{*}{ Total } \\
\hline & Never & $\begin{array}{l}\text { Less than once a month } \\
\text { to once a month }\end{array}$ & $\begin{array}{l}\text { Once a week to } \\
\text { nearly every day }\end{array}$ & \\
\hline Never & 206 & 56 * & 19 * & $281(64.4 \%)$ \\
\hline $\begin{array}{l}\text { Less than once a } \\
\text { month to once a month }\end{array}$ & $47^{* *}$ & 70 & 21 * & $138(31.7 \%)$ \\
\hline $\begin{array}{l}\text { Once a week to nearly } \\
\text { every day }\end{array}$ & 9 ** & $5^{* *}$ & 3 & $17(3.9 \%)$ \\
\hline Total & $262(60.1 \%)$ & $131(30.0 \%)$ & $43(9.9 \%)$ & $436(100.0 \%)$ \\
\hline
\end{tabular}

Note: McNemar test: 14.20; p-value $=0.003$. Cells on diagonal of table represent adolescents with unaltered binge drinking frequency.

* Adolescents with increased binge drinking;

** Adolescents with decreased binge drinking. 
having a father who drinks $(\mathrm{p}=0.001)$, having a mother who drinks $(\mathrm{p}<0.001)$ and a change in the risk of tobacco use on the part of the adolescent $(\mathrm{p}=0.016)$ (Table 2).

Using the autofit command, five constraints were imposed on the final model corresponding to five variables constrained to have their effects meet the parallel-lines assumption (frequency of religious services, mother drinks, mother's schooling, SVI and gender). The effects of these constrained variables were the same in both regressions. However, the effect of the variables "father drinks" and "increased risk of tobacco use" differed between the two regression models. The adjusted multiple

\section{Table 2}

Change in frequency of binge drinking according to independent variables among adolescents in two years of follow-up $(n=436)$. Belo Horizonte, Minas Gerais State, Brazil, 2012.

\begin{tabular}{|c|c|c|c|c|}
\hline Categories & $\begin{array}{c}\text { Total sample } \\
\text { n (\%) }\end{array}$ & $\begin{array}{l}\text { Without change } \\
\text { in binge drinking } \\
(\mathrm{n}=340) \\
\mathrm{n}(\%)\end{array}$ & $\begin{array}{l}\text { Increase in binge } \\
\text { drinking }(n=96) \\
n(\%)\end{array}$ & $\begin{array}{c}\text { p-value } \\
\text { (chi-square test } \\
\text { for trend) }\end{array}$ \\
\hline \multicolumn{5}{|c|}{ Socio-demographic and economic factors } \\
\hline \multicolumn{5}{|l|}{ Gender } \\
\hline Female & $260(59.6)$ & $178(68.5)$ & $48(18.5)$ & 0.260 \\
\hline Male & $176(40.4)$ & $101(57.4)$ & $48(27.3)$ & \\
\hline \multicolumn{5}{|l|}{ Type of school } \\
\hline Public & 331 (75.9) & $211(63.8)$ & $72(21.8)$ & 0.630 \\
\hline Private & $105(24.1)$ & $68(64.8)$ & $24(22.9)$ & \\
\hline \multicolumn{5}{|c|}{ Mother's schooling (years) } \\
\hline$\geq 8$ & $220(61.5)$ & $95(68.4)$ & $28(20.3)$ & 0.740 \\
\hline Up to 8 & $138(38.5)$ & $136(61.8)$ & $50(22.7)$ & \\
\hline \multicolumn{5}{|c|}{ SVI (adolescent's residence) } \\
\hline Less vulnerability & $227(52.1)$ & $139(61.2)$ & $48(21.1)$ & 0.100 \\
\hline Greater vulnerability & $209(47.9)$ & $140(66.9)$ & $48(22.9)$ & \\
\hline \multicolumn{5}{|c|}{ Frequency of religious services } \\
\hline Weekly/Daily & $151(34.6)$ & $102(67.6)$ & $21(13.9)$ & 0.004 \\
\hline Monthly & $203(46.6)$ & $125(61.6)$ & $54(26.6)$ & \\
\hline Never & $82(18.8)$ & $52(63.4)$ & $21(25.6)$ & \\
\hline \multicolumn{5}{|c|}{ Behavior of family members regarding alcohol intake } \\
\hline \multicolumn{5}{|l|}{ Family member drinks } \\
\hline No & $98(22.5)$ & $70(71.4)$ & $8(8.2)$ & $<0.001$ \\
\hline Yes & $338(77.5)$ & $209(61.8)$ & $88(26.0)$ & \\
\hline \multicolumn{5}{|l|}{ Father drinks } \\
\hline No & $215(49.3)$ & $153(71.2)$ & $29(13.5)$ & 0.001 \\
\hline Yes & $221(50.7)$ & $126(57.0)$ & $67(30.3)$ & \\
\hline \multicolumn{5}{|l|}{ Mother drinks } \\
\hline No & $276(63.3)$ & $187(67.8)$ & $45(16.3)$ & $<0.001$ \\
\hline Yes & $160(36.7)$ & $92(57.5)$ & $51(31.9)$ & \\
\hline \multicolumn{5}{|c|}{ Change in risk of use of other drugs * } \\
\hline \multicolumn{5}{|l|}{ Hazardous tobacco use } \\
\hline Unaltered/Reduced & $411(94.3)$ & $271(65.9)$ & $83(20.2)$ & 0.016 \\
\hline Increased & $13(5.7)$ & $8(32.0)$ & $13(52.0)$ & \\
\hline \multicolumn{5}{|l|}{ Hazardous marijuana use } \\
\hline Unaltered/Reduced & $420(96.3)$ & $274(65.2)$ & $89(21.2)$ & 0.463 \\
\hline Increased & $16(3.7)$ & $5(31.3)$ & $7(43.8)$ & \\
\hline
\end{tabular}

SVI: Social Vulnerability Index.

* Difference between risk of tobacco and marijuana use between 2010 and 2012. 
regression analysis revealed a greater chance of increase in binge drinking among adolescents who lived in areas of greater social vulnerability, those whose mothers consumed alcoholic beverages, those whose father consumed alcoholic beverages, those with an increased risk of tobacco use and those who attended religious services on a monthly basis rather than a weekly or daily basis in comparison to those with unaltered or decreased consumption. When the category "no change in frequency of binge drinking" was added to the "increased" category and evaluated in comparison to adolescents who demonstrated a reduction in the frequency of binge drinking, "father drinks" and "increased risk of tobacco use" lost statistical significance (Table 3).

Table 4 displays the beta values of the post hoc test.

\section{Discussion}

In the present study, changes in the frequency of binge drinking were analyzed in a group of adolescents enrolled at public and private schools in the city of Belo Horizonte and an increase in the prevalence of binge drinking was found in the follow-up period. Binge drinking is a serious problem in adolescence 33 , as the adolescent brain is sensitive to the impact of early alcohol exposure during this critical developmental period 34. It is important to note that these effects may be influenced by the age of exposure to alcohol and the amount consumed ${ }^{34}$. Some researchers state that the age of onset is associated with alcohol use among adolescents, binge drinking and the transition to both alcohol abuse and dependence 7,9,11,35. The increase in the prevalence of binge drinking in the present investigation was expected, considering the increase in age among the participants in this longitudinal study. In Brazil, the consumption of alcoholic beverages among adolescents is commonplace despite the law prohibiting the sale and consumption of alcohol beverages among individuals under the age of 18 36. A previous study developed in the 27 Brazilian state capitals with a sample of 14,714 adolescent students from public and private schools revealed that $32 \%$ engaged in binge drinking in the previous year and $20.9 \%$ engaged in this practice in the 30 days prior to the study 7 .

The present investigation has important limitations that may affect the interpretability of findings. First, since data collection was carried out in schools, it is possible that students who were

Table 3

Final partial odds proportional model *.

\begin{tabular}{llll}
\hline & OR & 95\%Cl & p-value \\
\hline Increased frequency of binge drinking vs. & & & \\
Unaltered + decreased frequency & & & \\
$\quad$ Male & 1.25 & $0.79-1.98$ & 0.331 \\
Greater social vulnerability & 1.64 & $1.01-2.68$ & 0.047 \\
Mother drinks & 1.75 & $1.05-2.92$ & 0.030 \\
Father drinks & 2.02 & $1.11-3.68$ & 0.021 \\
Increased risk of tobacco use & 2.82 & $1.07-7.52$ & 0.036 \\
Frequency of religious services: never + monthly & 2.10 & $1.30-3.38$ & 0.002 \\
Increased + unaltered frequency of binge drinking & & & \\
vs. Decrease in binge drinking & & & \\
Male & 1.25 & $0.79-1.98$ & 0.331 \\
Greater social vulnerability & 1.64 & $1.01-2.68$ & 0.047 \\
Mother drinks & 1.75 & $1.05-2.92$ & 0.030 \\
Father drinks & 0.88 & $0.42-1.72$ & 0.727 \\
Increased risk of tobacco use & 0.70 & $0.19-2.57$ & 0.591 \\
Frequency of religious services: never + monthly & 2.10 & $1.30-3.38$ & 0.002 \\
\hline
\end{tabular}

95\%Cl: 95\% confidence interval; OR: odds ratio.

* Model adjusted for mother's schooling. 
Table 4

Results of post hoc test computed to determine sample power (1- $\beta$ probability of error)

\begin{tabular}{llc}
\hline Independent variables & $\begin{array}{c}\text { Increased frequency of binge } \\
\text { drinking vs. Unaltered + } \\
\text { decreased frequency }\end{array}$ & $\begin{array}{c}\text { Increased + unaltered frequency } \\
\text { of binge drinking vs. Decreased } \\
\text { frequency }\end{array}$ \\
\hline Gender & 0.56 & 0.15 \\
Type of school & 0.05 & 0.06 \\
Mother's schooling & 0.07 & 0.20 \\
SVI & 0.07 & 0.61 \\
Frequency of religious services & 0.86 & 0.48 \\
Family members drink & 0.99 & 0.55 \\
Father drinks & 0.98 & 0.10 \\
Mother drinks & 0.97 & 0.31 \\
Hazardous tobacco use & 0.71 & 0.04 \\
Hazardous marijuana use & 0.45 & 0.24
\end{tabular}

SVI: Social Vulnerability Index.

often absent from class and those who developed serious alcohol-related problems and dropped out of school were left out of the sample. Second, despite emphasizing the importance of giving honest responses, the findings may have been underestimated due to self-censuring and/or a suspicion that school authorities could demand access to the answers on the questionnaires. Third, as the data were derived from self-administered questionnaires, memory lapses and a lack of attentiveness should be taken into consideration, despite the attempt to minimize these effects by showing the respondents pictures of standard portions of different types of alcoholic beverages. Fourth, information on the influence of friends and characteristics of friendship networks, such as density, size, quality of contacts, proximity and centrality, was not collected in the present study, despite the fact that binge drinking has been associated with such factors. Fifth, no investigation was conducted into the quality of the relationships between the adolescents and their parents, how long they had lived together or whether they engaged in regular conversations. According to the results of the post hoc test, the sample power was low for some variables, which may represent a type II error and fail to reveal significant associations. However, the test power for the variables of interest (risk of increased tobacco use, religiousness and family members who drink) demonstrates that the sample was sufficient for the evaluation of associations with binge drinking. The frequency of the response variable cannot be extrapolated to the student population of the city of Belo Horizonte.

In the present study, the increase in the frequency of binge drinking was fourfold greater among adolescents who exhibited an increase in hazardous tobacco use. Binge drinking is often associated with the use of other substances, such as cigarettes 37 . This association may be explained by common predisposing factors, such as the influence of peers, parental behavior regarding alcohol, tobacco and supervision 1 as well as aspects related to religious participation 8,38. In contrast to the present findings, Fisher et al. 39 conducted a cohort study in the United States and concluded that smoking did not appear to increase the risk of binge drinking among individuals who had initiated alcohol use. However, a longitudinal study conducted in Finland found a strong role of adolescent smoking in excessive alcohol use in adulthood, especially among females 1 . The authors suggest that studies on gender differences in the association between smoking and the future risk of alcohol problems are needed in current societies, since the predictive role of smoking in adolescence on future substance use and related problems is not entirely consistent.

The fact that parents consumed alcoholic beverages constituted another predictor of an increase in binge drinking among the adolescents in the present study. Mothers were found to have had the greatest influence on the drinking pattern of adolescents. A study involving European adolescents among whom substance use and the role of family structure were analyzed lends support to the 
hypothesis that having confidence in one's mother is inversely associated with the regular use of alcoholic beverages 40 . Adolescents who have love and support from their parents are less likely to engage in drug use and other risky behaviors 41 . A number of studies have demonstrated the role of family factors in binge drinking 4,19,42. The quality of an adolescent's relationship with his or her parents, which can be impaired by parental substance use, can also put adolescents at risk 40,41. A recent longitudinal study evaluated a reduction in alcohol consumption by 5,106 high school and college adolescents and its association to their parent's alcohol consumption. The results of this study revealed that when the student's father was a moderate or heavy drinker it was associated to there being a lesser probability of those students reducing their alcohol consumption 43.

Despite being a well-established determinant, the influence of socioeconomic status on health is not well understood and little research has focused on the effects of this aspect on health during adolescence 44 . In the present study, lower socioeconomic status was associated with an increase in the frequency of binge drinking among adolescents. Some studies have demonstrated that adolescents with a higher socioeconomic status have a greater propensity towards the use of alcoholic beverages and binge drinking 7,44. Goodman \& Huang 44 studied a sample of 15,112 adolescents and found that better socioeconomic status (evaluated based on parental schooling and household income) was associated with alcohol intake as well as tobacco, marijuana and cocaine use. In a recent study conducted with students aged 14 to 18 years in the five major regions of Brazil, nearly $32 \%$ of the sample had engaged in binge drinking in the previous year, while being in the highest socioeconomic segment doubled the risk of binge drinking among adolescents 7 . However, other studies have found an association between a lower socioeconomic status and greater alcohol consumption 15,16,29,45, while still others have found no significant association between socioeconomic status and alcohol intake 46,47. According to Pratta \& Santos 48, adolescents who reside in an environment that constitutes a threat to their health may become more vulnerable to certain daily situations.

Religious factors have been identified as having a protective effect against substance use in adolescence 49 . In the present study, a lesser frequency of religious participation was directly associated with an increase or no change in the frequency of binge drinking. It is possible that greater religious participation instills moral values and self-control skills or helps adolescents develop healthy social networks 49 . Sanchez et al. 22 found an inversely proportional relationship between frequent engagement in religious services (almost daily or at least weekly) and the abusive consumption of alcohol, which is in agreement with the present findings. Foster et al. 50 stress the importance of considering potential cognitive factors in the etiology and prevention of drinking. In a recent study, the authors found that spirituality and religiosity was negatively associated with drinking behavior, such that individuals scoring high in spirituality, religiosity and "benefit finding" reported drinking less alcohol and experiencing fewer negative alcohol-related consequences. The potential explanation is that benefit finding may provide psychological relief without seeking tension reduction or self-medication through alcohol. Therefore, psychological relief may be the underlying mechanism that reduces perceived stress and reduces the need to cope through drinking.

In the present study, the incidence of an increase in binge drinking was not associated with gender, although the sample was too small to detect such an association. While alcohol intake may be interpreted as a demonstration of masculinity 51 and has a facilitating effect on social interactions 33 , the consumption of alcoholic beverages has increased among females due to recent social advances, such as financial independence and the fact that adolescent girls currently have more freedom to frequent places that serve alcoholic beverages that were previously restricted to males 52 . An adolescent's self-perception regarding his/her lack of social skills and emotional involvement may favor the consumption of alcoholic beverages 19. In a study conducted in the northwest of England, the strength of the association between alcohol use and the prevalence of sexual activity among adolescents aged 13 and 14 increased incrementally with the greater frequency of alcohol use 53. While alcohol consumption may encourage adolescents to establish social ties, it can also lead to behaviors that place one's health at risk 3,54 .

Health-associated behaviors in adulthood are often initiated in adolescence. As problems that require treatment do not generally become evident until much later in life, primary prevention is crucial for adolescents 53 . According to Kraus et al. 55 , the frequency of binge drinking seems to be a better predictor of alcohol-related social problems than volume. Such problems, especially among 
drinkers with moderate intake per day, may be reduced by prevention strategies aimed at episodic heavy drinkers. Moreover, reducing the frequency of episodic heavy drinking may reduce overall alcohol consumption.

\section{Conclusions}

Determining the frequency of binge drinking is important to collective health, as this practice is associated with harm to health and well-being as well as the use of other psychotropic substances. Moreover, binge drinking can lead to dependence, with serious biological, psychological, behavioral and social consequences. The present findings demonstrate the influence of family and socioeconomic status on the occurrence of binge drinking and can assist in the establishment of public health policies directed at health promotion and prevention strategies on the family and community levels. Considering the cross-sectional nature of most scientific investigations, the present longitudinal study offers a greater understanding of the role of religious activities in the prevention of binge drinking, which is a relevant issue to public health in Brazil.

\section{Contributors}

K. O. Jorge conceived the study, collected data and wrote the first version, revised the manuscript for important intellectual content and read and approved the final version of the manuscript. R. C. Ferreira conducted the statistical analysis, contributed substantially to the interpretation of the results, revised the manuscript for important intellectual content and read and approved the final version of the manuscript. E. F. Ferreira and I. Kawachi contributed substantially to the interpretation of the results, revised the manuscript for important intellectual content and read and approved the final version of the manuscript. M. P. Vale revised the manuscript for important intellectual content and read and approved the final version of the manuscript. P. M. Zarzar conceived the study, contributed substantially to the interpretation of the results, revised the manuscript for important intellectual content and read and approved the final version of the manuscript.

\section{Acknowledgments}

The authors wish to thank the Fundação de Amparo à Pesquisa de Minas Gerais (FAPEMIG) for its support. 


\section{References}

1. Huurre T, Lintonen T, Kaprio J, Pelkonen M, Marttunen M, Aro H. Adolescent risk factors for excessive alcohol use at age 32 years. A 16-year prospective follow-up study. Soc Psychiatry Psychiatr Epidemiol 2010; 45:125-34.

2. Morleo M, Cook PA, Bellis MA, Smallthwaite L. Use of fake identification to purchase alcohol amongst 15-16 year olds: a cross-sectional survey examining alcohol access, consumption and harm. Subst Abuse Treat Prev Policy 2010; $5: 12$.

3. Reboussin BA, Song EY, Shrestha A, Lohman $\mathrm{KK}$, Wolfson M. A latent class analysis of underage problem drinking: evidence from a community sample of 16-20 year olds. Drug Alcohol Depend 2006; 83:199-209.

4. Sanchez ZM, Martins SS, Opaleye ES, Moura YG, Locatelli DP, Noto AR. Social factors associated to binge drinking: a cross-sectional survey among Brazilian students in private high schools. BMC Public Health 2011; 11:201.

5. Room R, Babor T, Rehm J. Alcohol and public health. Lancet 2005; 365:519-30.

6. Clausen T, Rossow I, Naidoo N, Kowal P. Diverse alcohol drinking patterns in 20 African countries. Addiction 2009; 104:1147-54.

7. Sanchez ZM, Locatelli DP, Noto AR, Martins SS. Binge drinking among Brazilian students: a gradient of association with socioeconomic status in five geo-economic regions. Drug Alcohol Depend 2013; 1:87-93.

8. Zarzar PM, Jorge KO, Oksanen T, Vale MP, Ferreira EF, Kawachi I. Association between binge drinking, type of friends and gender: a cross-sectional study among Brazilian adolescents. BMC Public Health 2012; 12:257.

9. Malta DC, Machado IE, Porto DL, Silva MMA, Freitas PC, Costa AWN, et al. Alcohol consumption among Brazilian adolescents according to the National Adolescent School-based Health Survey (PeNSE 2012). Rev Bras Epidemiol 2014; 17 Suppl 1:203-14.

10. Kim D, Subramanian SV, Kawachi I. Social capital and physical health: a systematic review of the literature. In: Kawachi I, Subramanian SV, Kim D, editors. Social capital and health. New York: Springer; 2008. p. 139-90.

11. Kalaydjian A, Swendsen J, Chiu W, Dierker L, Degenhardt L, Glantz M, et al. Sociodemographic predictors of transitions across stages of alcohol use, disorders and remission in the National Comorbidity Survey-Replication. Compr Psychiatry 2009; 50:299-306.

12. Madruga CS, Laranjeira R, Caetano R, Pinsky I, Zaleski M, Ferri CP. Use of licit and illicit substances among adolescents in Brazil-a national survey. Addict Behav 2012; 37:1171-5.

13. Viner RM, Taylor B. Adult outcomes of binge drinking in adolescence: findings from a UK national birth cohort. J Epidemiol Community Health 2007; 61:902-7.
14. Mistry R, McCarthy WJ, Yancey AK, Lu Y, Patel $\mathrm{M}$. Resilience and patterns of health risk behaviors in California adolescents. Prev Med 2009; 48:291-7.

15. Helasoja V, Lahelma E, Prättälä R, Petkeviciene J, Pudule I, Tekkel M. The sociodemographic patterning of drinking and binge drinking in Estonia, Latvia, Lithuania and Finland, 19942002. BMC Public Health 2007; 7:241.

16. Hamilton HA, Noh S, Adlaf EM. Perceived financial status, health and maladjustment in adolescence. Soc Sci Med 2009; 68:1527-34.

17. Lemstra M, Bennett NR, Neudorf C, Kunst A, Nannapaneni U, Warren LM, et al. A metaanalysis of marijuana and alcohol use by socioeconomic status in adolescents aged 10-15 years. Can J Public Health 2006; 99:172-7.

18. Galduróz JC, Caetano R. Epidemiology of alcohol use in Brazil. Rev Bras Psiquiatr 2004; 26:S3-6.

19. de Souza DP, Areco KN, da Silveira Filho DX. Alcohol and alcoholism among Brazilian adolescent public-school students. Rev Saúde Pública 2005; 39:585-92.

20. Hanson MD, Chen E. Socioeconomic status and health behaviors in adolescence: a review of the literature. J Behav Med 2007; 30:263-85.

21. Bartkowski JP, Xu X. Religiosity and teen drug use reconsidered: a capital perspective. Am J Prev Med 2007; 32:182-94.

22. Sanchez ZM, Opaleye ES, Chaves TV, Noto AR, Nappo SA. God forbids or mom disapproves? Religious beliefs that prevent drug use among youth. J Adolesc Res 2011; 26:591-616.

23. Castro DS, Sanchez ZM, Zaleski M, Alves HN, Pinsky I, Caetano R, et al. Sociodemographic characteristics associated with binge drinking among Brazilians. Drug Alcohol Depend 2012; 126:272-6.

24. Nonnemaker JM, McNeelyb CA, Blum RW. Public and private domains of religiosity and adolescent health risk behaviors: evidence from the National Longitudinal Study of Adolescent Health. Soc Sci Med 2003; 57:2049-54.

25. Martins-Oliveira JG, Jorge KO, Ferreira RC, Ferreira EF, Vale MP, Zarzar PM. Risk of alcohol dependence: prevalence, related problems and socioeconomic factors. Ciênc Saúde Coletiva 2016; 21:17-26.

26. Meneses-Gaya C, Zuardi AW, Loureiro SR, Hallak JE, Trzesniak C, de Azevedo Marques JM, et al. Is the full version of the AUDIT really necessary? Study of the validity and internal construct of its abbreviated versions. Alcohol Clin Exp Res 2010; 34:1417-24.

27. Lima CT, Freire AC, Silva AP, Teixeira RM, Ferrell M, Prince M. Concurrent and construct validity of the AUDIT in an urban Brazilian sample. Alcohol Alcohol 2005; 40:584-9.

28. Kelly T, Donovan J, Kinnane J, Taylor D. A comparison of alcohol screening instruments among under-aged drinkers treated in emergency departments. Alcohol Alcohol 2002; $37: 444-50$ 
29. Pinsky I, Sanchez ZM, Zaleski M, Laranjeira R, Caetano R. Patterns of alcohol use among Brazilian adolescents. Rev Bras Psiquiatr 2010; 32:242-9.

30. Nahas M, Ribeiro C, Esteves O, Moscovitch S, Martins VL. O mapa da exclusão social de Belo Horizonte: metodologia de construção de um instrumento de gestão urbana. Cadernos de Ciências Sociais 2000; 7:75-88.

31. Henrique IF, Micheli D, Lacerda RB, Lacerda LA, Formigoni MLOS. Validation of the Brazilian version of the Alcohol, Smoking and Substance Involvement Screening Test (ASSIST). Rev Assoc Méd Bras (1992) 2004; 50:199-206.

32. Williams R. Generalized ordered logit/partial proportional odds models for ordinal dependent variables. Stata J 2006; 6:58-82.

33. Moral MV, Rodríguez FJ, Ovejero A. Correlatos psicosociales del consumo de sustancias psicoactivas en adolescentes españoles. Salud Pública Méx 2010; 52:406-15.

34. Maldonado-Devincci AM, Badanichb KA, Kirstein CL. Alcohol during adolescence selectively alters immediate and long-term behavior and neurochemistry. Alcohol 2010; 44:57-66.

35. Morean ME, Kong G, Camenga DR, Cavallo DA, Connell C, Krishnan-Sarin S. First drink to first drunk: age of onset and delay to intoxication are associated with adolescent alcohol use and binge drinking. Alcohol Clin Exp Res 2014; 38:2615-21.

36. Romano M, Duailibi S, Pinsky I, Laranjeira R. Alcohol purchase survey by adolescents in two cities of State of São Paulo, Southeastern Brazil. Rev Saúde Pública 2007; 41:495-501.

37. Merline A, Jager J, Schulenberg JE. Adolescent risk factors for adult alcohol use and abuse: stability and change of predictive value across early and middle adulthood. Addiction 2008; 103:84-99.

38. Sanchez ZM, Opaleye E, Martins S, Ahluwalia JS, Noto AR. Adolescent gender differences in the determinants of tobacco smoking: a cross sectional survey among high school students in São Paulo. BMC Public Health 2010; 10:748.

39. Fisher LB, Miles IW, Austin SB, Camargo Jr. CA, Colditz GA. Predictors of initiation of alcohol use among US adolescents findings from a prospective cohort study. Arch Pediatr Adolesc Med 2007; 161:959-66.

40. McArdle P, Wiegersma A, Gilvarry E, Kolte B, McCarthy S, Fitzgerald M, et al. European adolescent substance use: the roles of family structure function and gender. Addiction 2002; 97:329-36.

41. Kodjo CM, Klein JD. Prevention and risk of adolescent substance abuse. The role of adolescents, families and communities. Pediatr Clin North Am 2002; 49:257-68.

42. Schenker M, Minayo MCS. A importância da família no tratamento do uso abusivo de drogas: uma revisão da literatura. Cad Saúde Pública $2004 ; 20: 649-59$.
43. Swann CA, Sheran M, Phelps D. Factors associated with reductions in alcohol use between high school and college: an analysis of data from the College Alcohol Study. Subst Abuse Rehabil 2014; 5:13-23.

44. Goodman E, Huang B. Socioeconomic status, depressive symptoms, and adolescent substance use. Arch Pediatr Adolesc Med 2002; 156:448-53.

45. Mendoza-Sassi RA, Béria JU. Prevalence of alcohol use disorders and associated factors: a population-based study using AUDIT in southern Brazil. Addiction 2004; 98:799-804.

46. Muza GM, Bettiol H, Muccillo G, Barbieri MA. The consumption of psychoactive substances by adolescents in schools in Ribeirão Preto, SP (Brazil). I-Prevalence of consumption by sex, age and substance. Rev Saúde Pública 1997; 31:163-70.

47. Strauch ES, Pinheiro RT, Silva RA, Horta BL. Alcohol use among adolescents: a populationbased study. Rev Saúde Pública 2009; 43:64755.

48. Pratta EM, Santos MA. Adolescence and the consumption of psychoactive substances: the impact of the socioeconomic status. Rev Latinoam Enferm 2007; 15:806-11.

49. Mellor JM, Freeborn BA. Religious participation and risky health behaviors among adolescents. Health Econ 2011; 20:1226-40.

50. Foster DW, Quist MC, Young CM, Bryan JL, Nguyen M, Neighbors C. Benefit finding as a moderator of the relationship between spirituality/religiosity and drinking. Addict Behav 2013; 38:2647-52.

51. Campbell H. The glass phallus: public masculinity and drinking in rural New Zealand. Rural Sociol 2000; 65:562-81.

52. Esnaola I. Autoconcepto y consumo de drogas legales en la adolescencia. Rev Esp Drogodepend 2006; 1:57-66.

53. Truong KD, Sturm R. Alcohol environments and disparities in exposure associated with adolescent drinking in California. Am J Public Health 2009; 99:264-70.

54. Phillips-Howard PA, Bellis MA, Briant LB, Jones H, Downing J, Kelly IE, et al. Wellbeing, alcohol use and sexual activity in young teenagers: findings from a cross-sectional survey in school children in North West England. Subst Abuse Treat Prev Policy 2010; 5:27.

55. Kraus L, Baumeister SE, Pabst A, Orth B. Association of average daily alcohol consumption, binge drinking and alcohol-related social problems: results from the German epidemiological surveys of substance abuse. Alcohol Alcohol 2009; 44:314-20. 


\section{Resumo}

Objetivou-se investigar mudanças na frequência de consumo excessivo de álcool (binge drinking) e fatores associados na cidade de Belo Horizonte, Minas Gerais, Brasil. A amostra incluiu 436 adolescentes. Os dados foram coletados com o Alcohol Use Disorders Identification Test e o Alcohol, Smoking and Substance Involvement Screening Test. A regressão logística multivariada foi usada na análise dos dados. Observamos um aumento na frequência de consumo excessivo de álcool entre adolescentes que viviam em áreas de maior vulnerabilidade social $(O R=1,64$; IC95\%: 1,01-2,68), com mães que consumiam bebidas alcoólicas $(O R=1,75$; IC95\%: 1,05-2,92), com pais que consumiam bebidas alcoólicas $(O R=2,02$; IC95\%: 1,11-3,68), expostos a risco aumentado de tabagismo $(O R=2,82$; IC95\%: 1,07-7,42) e que participavam de atividades religiosas $(O R=2,10$; IC95\%: 1,30-3,38). O conhecimento dos fatores associados a mudanças na frequência de consumo excessivo de álcool entre adolescentes pode auxiliar na elaboração de políticas públicas dirigidas à promoção da saúde e à prevenção de desfechos adversos.

Bebedeira; Bebidas Alcoólicas; Adolescente

\section{Resumen}

El objetivo fue investigar cambios en la frecuencia de consumo excesivo de alcohol (binge drinking) $y$ sus factores asociados en la ciudad de Belo Horizonte, Minas Gerais, Brasil. La muestra incluyó a 436 adolescentes. Los datos fueron recogidos con el Alcohol Use Disorders Identification Test y el Alcohol, Smoking and Substance Involvement Screening Test. Se usó la regresión logística multivariada en el análisis de datos. Observamos un aumento en la frecuencia de consumo excesivo de alcohol entre adolescentes que vivian en áreas de mayor vulnerabilidad social $(O R=1,64$; IC95\%: 1,01-2,68), con madres que consumian bebidas alcohólicas $(O R=1,75$; IC95\%: 1,05-2,92), con padres que consumían bebidas alcohólicas $(O R=$ 2,02; IC95\%: 1,11-3,68), expuestos a riesgo aumentado de tabaquismo (OR = 2,82; IC95\%: 1,07$7,42)$ y que practicaban una religión $(O R=2,10$; IC95\%: 1,30-3,38). El conocimiento de los factores asociados a cambios en la frecuencia de consumo excesivo de alcohol entre adolescentes puede ayudar en la elaboración de políticas públicas, dirigidas a la promoción de la salud y a la prevención de desenlaces adversos.

Borrachera; Bebidas Alcohólicas; Adolescente
Submitted on 04/Nov/2015

Final version resubmitted on $26 / \mathrm{Feb} / 2016$

Approved on 18/Apr/2016 